ISSN 1678-992X

\title{
Trophic ecology of citrus pests based on stable isotope analysis
}

\author{
Adelino de Santi-Júnior, Victor Wilson Botteon*, Thiago Mastrangelo, Marcelo Zacharias Moreira
}

University of São Paulo/CENA, Av. Centenário, 303 - 13416000 - Piracicaba, SP - Brazil.

*Corresponding author <victor.botteon@usp.br>

Edited by: Alberto Soares Corrêa

Received December 15, 2016

Accepted July 31, 2017
ABSTRACT: Macrodactylus pumilio Burm. (Coleoptera: Scarabeidae) and Naupactus cervinus (Boh.) (Coleoptera: Curculionidae) are considered primary pests in citrus crops in Brazil, causing damage to plants and decreasing productivity. However, few studies investigate the ecology of these insects. In this context, the use of stable isotopes analysis (SIA) emerges as an alternative technique to conventional studies of behavioral ecology because it is faster and may explain feeding behavior based on the food source for each species. Field sampling and laboratory experiments were carried out to examine the changes of carbon and nitrogen stable isotope ratios $\left(\delta^{13} \mathrm{C}\right.$ and $\left.\delta^{15} \mathrm{~N}\right)$ among pests and host plants $\left(\mathrm{C}_{3}\right.$ citrus and $\mathrm{C}_{4}$ grasses), providing means to examine trophic interactions. Beetles were collected at the municipality of Gavião Peixoto, São Paulo State, identified and kept at $5{ }^{\circ} \mathrm{C}$ in saturated saline solution until the SIA. Two patterns for both species were found: $\delta^{13} \mathrm{C}$ value for $N$. cervinus was $-23.6 \%$ and $-13 \%$ for $M$. pumilio, indicating similarity between the results of $\delta^{13} \mathrm{C}$ of $N$. cervinus and citrus plants $(-26 \%)$ and dependence on grasses (-12\%) for $\mathrm{M}$. pumilio individuals. The mean $\delta^{15} \mathrm{~N}$ value was 4.3 and 5.8 $\%$ for citrus plants and grass leaves, respectively, and the mean $\delta^{15} \mathrm{~N}$ value was $4.4 \%$ for $\mathrm{N}$. cervinus and $4.9 \%$ for $M$. pumilio. The results showed a higher affinity of $N$. cervinus for citrus roots since the larval stage compared with the alternative diet on $M$. pumilio.

Keywords: Macrodactylus pumilio, Naupactus cervinus, $\delta^{13} \mathrm{C}, \delta^{15} \mathrm{~N}$

\section{Introduction}

Brazilian citrus crop face several phytosanitary problems, despite being one of the most important agricultural activities in the country. Some phytosanitary issues refer to the occurrence of Macrodactylus pumilio Burm., 1855 (Coleoptera: Scarabeidae) and Naupactus cervinus (Boh., 1840) (Coleoptera: Curculionidae), which are beetles considered primary pests in citrus orchards that cause direct and indirect damage to plants (Guedes and Parra, 2004; Guedes et al., 2005; Lanteri et al., 2002).

The knowledge of the behavior and life cycles of these species are necessary for their rational and economic management. Both adult and larval stages of these species are polyphagous and have been recorded feeding on a wide variety of cultivated plants and weeds (Chadwick, 1965; Lanteri et al., 2002; Masaki and Kadoi, 1997). Most citrus orchards in Brazil have conducted careless weed suppression, resulting in soils covered with grasses and surrounding vegetation (Cividanes et al., 2010), which may show differences to the citrus fruits. Brazilian entomologists have investigated the influence of such scenario on the feeding behavior of both species.

To better understand the feeding behavior of these beetles in the study site, the use of stable isotope analysis (SIA) emerges as an alternative technique to conventional studies on behavioral ecology. The different forms of carbon fixation lead to different amounts of isotopes of this element in plants tissue (isotopic composition), reflecting the diet of consumers (phytophagous beetles in case) through isotopic determination in their tissues (Hesslein et al., 1993; Hood-Nowotny and Knols, 2007; Hyodo et al., 2010; Hyodo, 2015).
The stable nitrogen isotope can also help understand trophic relations in food webs, where consumers reflect the isotopic composition of primary producers, reflecting environmental characteristics. The isotopic variation of plants that cannot fix atmospheric nitrogen is generally dependent on soil isotopic abundance and fertilization variation (Choi et al., 2002). Nonetheless, nitrogen isotope values tend to increase in many food chains with successive trophic transfer, each increasing the concentration from 3 to $5 \%$ in $\delta^{15} \mathrm{~N}$ (Minagawa and Wada, 1984).

This study aimed to trace the source on the diet of $M$. pumilio and $N$. cervinus beetles in an orange orchard using carbon and nitrogen stable isotope analyses in order to better understand the biological behavior of these pests.

\section{Materials and Methods}

\section{Sampling site}

The study was carried out in a citrus farming area of approximately $45 \mathrm{ha}$, located in the municipality of Gavião Peixoto, São Paulo State, Brazil $\left(21^{\circ} 49^{\prime} 10^{\prime \prime}\right.$ S, $\left.48^{\circ} 24^{\prime} 51^{\prime \prime} \mathrm{W}\right)$. The site is 520 meters a.s.l., with Aw climate (Köppen-Geiger climate classification system) (Alvares et al., 2013). Beetles were sampled by the "beating cloth" method from Nov 2010 to Oct 2011. Citrus and grass (weed) samples were randomly collected in order to determine the isotopic composition of plants that participate in the diet of beetles.

Adult individuals of $N$. cervinus and M. pumilio were collected at the flowering period of citrus plants, accompanied by population outbreak of these pests in the field, as soon as adults emerged. Adults were col- 
lected and their food was evaluated. Adults fed on new leaves and the difference between the root and leaf is expected to be small since organic compounds that form the roots are generated in the leaves (Badeck et al., 2005). The specimens of $N$. cervinus were identified to the generic level following the keys of Guedes et al. (2005) and specific identifications of specimens of $M$. Pumilio were done by comparison with specimens deposited at the ESALQ/USP Entomology Museum. The specimens were kept at $5{ }^{\circ} \mathrm{C}$ in saturated saline solution until the stable isotopes analysis.

\section{Stable isotope analysis (SIA)}

SIA of $\mathrm{C}$ and $\mathrm{N}$ were performed in order to determine the concentration of these isotopes in the tissues (beetles and plants). Stable isotope ratios are thus reported in delta $(\delta)$ notation, calculated by $\delta \mathrm{X}=\left[\left(\mathrm{R}_{\text {sample }}{ }^{\prime}\right.\right.$ $\mathrm{R}_{\text {standard }}$ l -1$]$, where $\delta \mathrm{X}$ refer to $\delta^{13} \mathrm{C}$ or $\delta^{15} \mathrm{~N}$, and $\mathrm{R}$ is the molar ratio of heavy to light isotopes $\left({ }^{13} \mathrm{C} /{ }^{12} \mathrm{C}\right.$ or $\left.{ }^{15} \mathrm{~N} /{ }^{14} \mathrm{~N}\right)$. Isotope ratios are expressed in per mil (\%o) relative difference to the ratio of international reference standards $\left(\mathrm{R}_{\text {standard }}\right)$, which are Vienna PeeDee Belemnite (VPDB) and Atmospheric Nitrogen for carbon and nitrogen, respectively. Depending on photosynthetic mode, stable carbon isotope values range from about -34 to $-24 \%$ in $\mathrm{C}_{3}$-type photosynthesis (higher plants like citrus) and from -14 to $-9 \%$ in the $\mathrm{C}_{4}$-type photosynthesis (many grasses) (Deines, 1980; Smith and Epstein, 1971).

The heads of 26 adult individuals of $N$. cervinus and 20 of $M$. Pumilio were analyzed and compared to the average of the isotopic values of leaves of grasses and citrus plants in order to relate the $\delta^{13} \mathrm{C}$ or $\delta^{15} \mathrm{~N}$ values of beetles to the rate of these sources in their diet. The head was chosen for analysis because it is the most sclerotized part of the insect body and may represent the whole diet for a larger period in the life of a beetle, in addition to excluding the most recent ingested food.

In all samples, heads of the beetles and dried material of plant samples $( \pm 3 \mathrm{mg})$, were enclosed in tin capsules and analyzed in an elemental analyzer, coupled with an Isotope ratio mass spectrometer. Results were normalized to the international standards through the use of secondary reference materials (NBS-19, NBS22, IAEA-N1, IAEA-N2) (Ehleringer and Rundel, 1989; Coplen, 1994). An in-house working standard (sugarcane leaf) was used for QC every 11 samples in each run, from where the precision was evaluated as better than $0.15 \%$ for both elements. Each sample was analyzed twice to obtain the mean values with precision better of $0.3 \%$.

The rate of citrus in the food source was estimated using a isotope mass balance linear mixing model through $\% \mathrm{C}_{3}=\left(\delta \mathrm{X}-\delta \mathrm{C}_{4}\right) /\left(\delta \mathrm{C}_{3}-\delta \mathrm{C}_{4}\right)$; where $\delta \mathrm{X}$ is the isotopic value of the analyzed beetle, $\delta \mathrm{C}_{3}$ and $\delta \mathrm{C}_{4}$ are the mean isotopic carbon value of citrus plants and grasses, respectively, and considering the enrichment of $+1 \%$ between trophic levels for both plants. To evaluate tro- phic levels, $+3.4 \%$ was added to the food source $\delta^{15} \mathrm{~N}$ values (Post, 2002).

\section{Data analysis}

Homogeneity of variances and normality of model residuals were checked in all instances. Initial analyses used the Shapiro-Wilk test for data distribution. The mean isotopic values and the percentage of carbon derived from citrus and grasses, the end-members of the linear mixing model, were compared by the Tukey honestly significant difference (HSD) test $(\alpha=0.05)$. The analyses were performed by the statistical program SAS 9.1 (SAS Institute, 2003).

\section{Results}

The mean $\delta^{13} \mathrm{C}$ value of citrus plants $\left(\mathrm{C}_{3}\right)$ was -25.7 $\pm 0.2 \%$, while for grass leaves $\left(\mathrm{C}_{4}\right)$, it was $-12 \pm 0.1 \%$, and $+1 \%$ was added to them as a discrimination factor for direct comparison to the trophic level of the consumer. Besides, $+1 \%$ was added to the $\mathrm{C}_{3}$ carbon isotope values in order to couple to the difference between leaves and plant roots (Badeck et al., 2005). Mean $\delta^{13} \mathrm{C}$ value for $N$. cervinus was $-23.6 \pm 0.3 \%$ and for $M$. pumilio was $-13 \pm 0.4 \%$. Clearly two patterns for both species were found where most individuals are clustered while some tend to show a mixture of carbon sources. The dispersion of $\delta^{13} \mathrm{C}$ and $\delta^{15} \mathrm{~N}$ values in the tissues of beetles can be seen in Figure 1. Comparisons showed similarity between the results of $\delta^{13} \mathrm{C}$ of $N$. cervinus and citrus plants $\left.\bigcup_{0.95} \mathrm{~F}_{1,53}=0.01158 ; p=0.91471\right)$. Both were different of $M$. pumilio and grasses $\delta^{13} \mathrm{C}$ values, which were also different from each other (Table 1).

The carbon isotopic analysis showed a small degree of mixing of $\mathrm{C}_{3}$-type and $\mathrm{C}_{4}$-type plants in the diet of one species. The results of $N$. cervinus indicate that carbon comes from $\mathrm{C}_{3}$ plants (including citrus) on $100 \%$ of them, with a minimum of 54 up to $83 \%$ in four individuals, and contributions higher than $90 \%$ for the others. On the other hand, M. pumilio individuals displayed values that indicate higher dependence on grasses for

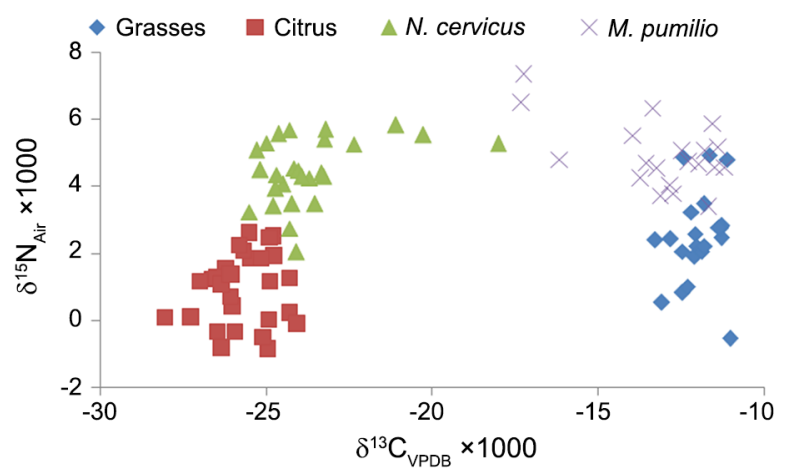

Figure 1 - Dispersion of $\delta^{13} \mathrm{C}$ and $\delta^{15} \mathrm{~N}$ values of citrus and grasses, and two of their pests Naupactus cervinus and Macrodactylus pumilio. 
Table 1 - Mean isotopic composition of citrus, grass and Coleoptera species (Naupactus cervinus and Macrodactylus pumilio) after adding the discrimination factor for carbon and nitrogen (see text).

\begin{tabular}{lcc}
\hline & $\delta^{13} \mathrm{C} \%$ versus VPDB & $\delta^{15} \mathrm{~N} \%$ versus $\mathrm{N}_{2}$ AIR \\
\hline Citrus & $-23.7 \pm 0.2 \mathrm{a}^{*}$ & $+4.3 \pm 0.2 \mathrm{a}$ \\
Naupactus cervinus & $-23.6 \pm 0.3 \mathrm{a}$ & $+4.4 \pm 0.2 \mathrm{a}$ \\
Macrodactylus pumilio & $-13 \pm 0.4 \mathrm{~b}$ & $+4.9 \pm 0.2 \mathrm{a}$ \\
Grass (Poaceae) & $-11 \pm 0.1 \mathrm{c}$ & $+5.8 \pm 0.3 \mathrm{~b}$ \\
\hline
\end{tabular}

${ }^{*}$ Means $( \pm$ SE) followed by the same letters in the columns do not differ significantly by the Tukey test $(\alpha=0.05)$.

$100 \%$ of the individuals, but with higher variation. Carbon derived from $\mathrm{C}_{4}$ grasses contributed to a minimum of $52 \%$ in two individuals, $60 \%$ in another, and from 75 up to $95 \%$ in the others. None of the $N$. cervinus showed typical $\mathrm{C}_{4}$ plant values and none of the M. pumilio showed typical $\mathrm{C}_{3}$ plant values.

Mean $\delta^{15} \mathrm{~N}$ values were $4.3 \pm 0.2$ and $5.8 \pm 0.3$ \%o for citrus plants $\left(\mathrm{C}_{3}\right)$ and grass leaves $\left(\mathrm{C}_{4}\right)$, respectively. The mean $\delta^{15} \mathrm{~N}$ value for $N$. cervinus was $4.4 \pm$ $0.2 \%$ and for $M$. pumilio was $4.9 \pm 0.2 \%$. By adding the generally accepted discrimination factor of $3.4 \%$ for one trophic level to the $\delta^{15} \mathrm{~N}$ values of the primary food sources evaluated (Post, 2002), only grass was significantly different (enriched) in terms of $\delta^{15} \mathrm{~N}$ values $l_{0.95} \mathrm{~F}_{1,48}=19.854 ; p<10^{-3}$; Table 1 ).

\section{Discussion}

Results from field sampling and laboratory analyses suggested that the mean values of $\delta^{13} \mathrm{C}$ were indicative of preferential consumption of $\mathrm{C}_{3}$ plants on $N$. cervinus and indicative of alternative diet on $M$. pumilio in the citrus orchard studied. Adult beetles were collected at the flowering period of citrus plants, accompanied by population outbreak of these pests in the field, as soon as adults emerged. As the larval cycle is long and occurs in the soil, the highly sclerotized head of the adults might reflect the larval phase diet. The data evidenced some mixing of $\mathrm{C}_{3}$-type and $\mathrm{C}_{4}$-type plants in the diet of adults, a possible reflection of diet post-larval stage, since the heads of adults were used in the stable isotopes analysis (SIA). Heads are highly sclerotized regions, showing that M. pumilio might feed on $\mathrm{C}_{4}$-type plants in their larval phase.

Plants reuse nitrogen with greater frequency than animals do (Gannes et al., 1998). Among consumers, there is $\delta^{15} \mathrm{~N}$-enrichment when compared to diets. Consequently, animals from higher trophic levels usually present higher $\delta^{15} \mathrm{~N}$ values than animals of lower trophic levels do, enabling studies on food webs through the isotopic analysis (McCutchan Jr. et al., 2003). The $\delta^{15} \mathrm{~N}$ values allow to study the nitrate source, its uptake into the food web and estimation of the trophic level by measuring the isotopic composition of amino acids of consumers (Chikaraishi et al., 2011). In this case, $\delta^{15} \mathrm{~N}$ showed values less conclusive when compared to $\delta^{13} \mathrm{C}$ values because the beetles are phytophagous in the same area, reflecting no significant difference in terms of $\delta^{15} \mathrm{~N}$ values.

The stable isotopes analysis is an important tool to study invertebrate food webs and movements in farmland (Lavandero et al., 2004). However, stable isotope values of farmland invertebrates have been reported for a few crop types only and it is not a technique commonly used in integrated pest management (Girard et al., 2011; Prasifka and Heinz, 2004). The advantage of using SIA to examine resource partitioning is that stable isotopes are naturally occurring tracers and are safe, non-radioactive, assimilated into the larval body, intrinsically incorporated into the tissues of organisms via food and water sources (Hobson and Wassenaar, 2008; Hood-Nowotny and Knols, 2007; Hyodo et al., 2015). Stable isotopes in body tissue can be used, therefore, as biological markers to determine larval food, with differences in isotope values for insects fed on $\mathrm{C}_{3}$-type or $\mathrm{C}_{4}$-type based hosts (Boecklen et al., 2011).

Larvae of M. pumilio and N. cervinus spend a significant period of their life cycle in the soil, depending on several factors, including structure, texture, soil moisture and the occurrence of other conditions (Guedes et al., 2007; Masaki and Nakahara, 2000). During the larval stage, both species develop in the soil until pupation, feeding on plant roots in the study area and causing injuries that favor the entry of pathogens (Guedes et al., 2002). In adult stage, these phytophagous beetles usually feed on flowers and leaves of the citrus plant. After mating, females of $M$. pumilio usually return to the soil to lay eggs, while females of $N$. cervinus lay eggs underneath fruit calices, with the larvae sinking in the soil for further development and pupation, as soon as they emerged (Guedes and Parra, 2004; Lanteri et al., 2002).

Polyphagous insects tend to have a hierarchy of preference and not all hosts are likely to be equally preferred or have equal value for growth, survival and influence on adult longevity and fecundity (Maher and Logan, 2004; Thompson, 1998). Farming practices, such as cultivation of different plant species and keeping grasses on farmlands, can cause changes in habitat structure and refuge for phytophagous insects. Vegetation in the vicinity changes the habitat structure, influencing the availability and distribution of resources and the foraging behavior of insects (Darling and Bayne, 2010). Differences of foraging behavior between species enable to explore the importance of food sources and the dispersal of insects across habitats in order to better understand functional roles and knowledge to be applied in integrated pest management (Schellhorn et al., 2014).

In addition to more comprehensive food source sampling, SIA may be useful in studying other ecological aspects of pests and natural enemies in farmlands (Oulhote et al., 2011). In order to determine the type of host plant on which the polyphagous corn pest Ostrinia nubilalis (Hübner, 1796) (Lepidoptera: Crambidae) feed during the larvas stage, Ponsard et al. (2004) performed 
experiments using SIA to quantify mating rates, spatial distribution and oviposition within and between species. Wise et al. (2006) studied generalist predator species engaged in multichannel omnivores using SIA and the results showed that the hunting mode influenced the extent to which these predators used prey from grazing and epigeic food webs. According to Ye et al. (2014), peanut was a more effective refuge to sustain Bt-susceptible bollworm individuals and reduce the risk of development of a Btresistant biotype. Ouyang et al. (2015) traced dietary origins of the predatory beetle Propylea japonica (Thunberg) (Coleoptera: Coccinellidae) based on the values of $\delta^{15} \mathrm{~N}$ and $\delta^{13} \mathrm{C}$, in order to understand their roles in the food web and provide information to develop strategies for effective conservation in agroecosystems.

The results of this study allowed to interpret isotope data for source identification and differences in larval isotopic composition of $N$. cervinus and M. pumilio as evidence of resource partitioning and distinct habits to explore food resources in the agroecosystem (Oulhote et al., 2011). Stable isotope ratios of diets are reflected in diets of consumers and the analysis showed it was a useful tool in reconstructing diets, characterizing trophic relationships, elucidating patterns of resource allocation and constructing food webs (Boecklen et al., 2011; Hyodo, 2015; Rounick and Winterbourn, 1986).

In general, SIA seems a natural alternative to mark arthropods in agricultural systems, enabling to study the energy flow without direct observation and contributing to better understand agricultural food webs and ecology behavior of pests and natural enemies, providing information to develop strategies for their effective control efforts within the agricultural landscape. The results of the stable isotopes analysis showed higher affinity for $\mathrm{C}_{3}$ plants (citrus), due to the dominance of these plants in the field and in the diet of $N$. cervinus during the larval stage, compared with the diet of $M$. pumilio in immature stage, which had indicative of alternative diet and preference for grasses. Further studies are necessary to evaluate the turnover rate and isotopic compositions throughout the biological cycle and during the metamorphosis to better understand ecological and behavioral aspects of these polyphagous species.

\section{Acknowledgments}

We thank the São Paulo Research Foundation (FAPESP process 2009/12265-3) and the Coordination for the Improvement of Higher Level Personnel (CAPES), for financial support and for providing a scholarship to the first author. We also thank to the reviewers that greatly contributed to the manuscript.

\section{References}

Alvares, C.A.; Stape, J.L.; Sentelhas, P. C.; de Moraes, G.; Leonardo, J.; Sparovek, G. 2013. Köppen's climate classification map for Brazil. Meteorologische Zeitschrift 22(6): 711-728.
Badeck, F.W.; Tcherkez, G.; Nogués, S.; Piel, C.; Ghashghaie, J. 2005. Post-photosynthetic fractionation of stable carbon isotopes between plant organs-a widespread phenomenon. Rapid Commun. Rapid Communications in Mass Spectrometry 19: 1381-1391.

Boecklen, W.J.; Yarnes, C.T.; Cook, B.A.; James, A.C. 2011. On the use of stable isotopes in trophic ecology. Annual Review of Ecology, Evolution and Systematics 42: 411-440.

Chadwick, C.E. 1965. A review of Fuller's rose weevil (Pantomorus cervinus (Boh.) (Col., Curculionidae). Journal of the Entomological Society of Australia 2: 1-20.

Chikaraishi, Y.; Ogawa, N.O.; Doi, H.; Ohkouchi, N. 2011. ${ }^{15} \mathrm{~N} /{ }^{14} \mathrm{~N}$ ratios of amino acids as a tool for studying terrestrial food webs: a case study of terrestrial insects (bees, wasps and hornets). Ecological Research 26: 835-844.

Choi, W.J.; Lee, S.M.; Ro, H.M.; Kim, K.C.; Yoo, S.H. 2002. Natural ${ }^{15} \mathrm{~N}$ abundances of maize and soil amended with urea and composted pig manure. Plant and Soil 245: 223-232.

Cividanes, F.J.; Araújo, E.S.; Ide, S.; Galli, J.C. 2010. Distribution and habitat preference of Carabidae and Staphylinidae (Coleoptera) in an orange orchard and a forest fragment. Florida Entomologist 93: 339-345.

Coplen, T.B. 1994. Reporting of stable hydrogen, carbon, and oxygen isotopic abundances. Pure and Applied Chemistry 66: 273-276.

Darling, A.F.; Bayne, E.M. 2010. The Potential of stable isotope $\left({ }^{13} \mathrm{C},{ }^{15} \mathrm{~N}\right)$ analyses for measuring foraging behaviour of animals in disturbed boreal forest. Ecoscience 17: 73-82.

Deines, P. 1980. The isotopic composition of reduced organic carbon. p. 329-406. In: Fritz, P.; Fontes, J., eds. Handbook of environmental isotope geochemistry. Elsevier, Amsterdam, The Netherlands.

Ehleringer, J.R.; Rundel, P.W. 1989. Stable isotopes: history, units, and instrumentation. p.1-16. In: Rundel, P.W.; Ehleringer, J.R.; Nagy, K.A., eds. Stable isotopes in ecological research. Springer-Verlag, New York.

Gannes, L.Z.; Carlos Rio, M. Del; Koch, P. 1998. Natural abundance variations in stable isotopes and their potential uses in animal physiological ecology. Comparative Biochemistry and Physiology Part A: Molecular \& Integrative Physiology 119: 725-737.

Girard, J.; Baril, A.; Mineaub, P.; Fahrigc, L. 2011. Carbon and nitrogen stable isotope ratios differ among invertebrates from field crops, forage crops, and non-cropped land uses. Ecoscience 18: 98-109.

Guedes, J.V.C.; Parra, J.R.P.; Yamamoto, P.T. 2002. Occurrence of citrus root curculionids in São Paulo. Laranja 23: 308-320 (in Portuguese, with abstract in English).

Guedes, J.V.C.; Parra, J.R.P. 2004. Oviposition of citrus root weevils. Ciência Rural 34: 673-678 (in Portuguese, with abstract in English).

Guedes, J.V.C.; Lanteri, A.A.; Parra, J.R.P. 2005. Key for identification, occurrence and distribution of citrus-root weevils in São Paulo and Minas Gerais. Neotropical Entomology 34: 577-584 (in Portuguese, with abstract in English).

Guedes, J.V.C.; Parra, J.R.P.; Fiorin, R.A. 2007. Biological aspects of the adult phase of the citrus root weevils. Ciência Rural 37: 304-307 (in Portuguese, with abstract in English). 
Hesslein, R.H.; Hallard, K.A.; Ramlal, P. 1993. Re-placement of sulfur, carbon, and nitrogen, in tissue of growing broad whitefish (Coregonus nasus) in response to a change in diet traced by $\delta^{34} S, \delta^{13} \mathrm{C}$, and $\delta^{15} \mathrm{~N}$. Canadian Journal of Fisheries and Aquatic Sciences 50: 2071-2076.

Hobson, K.A.; Wassenaar, L.I. 2008. Tracking animal migration with stable isotopes. Academic Press, Amsterdam, The Netherlands.

Hood-Nowotny, R.; Knols, B. 2007. Stable isotope methods in biological and ecological studies of arthropods. Entomologia Experimentalis et Applicata 124: 3-16.

Hyodo, F.; Kohzu, A.; Tayasu, I. 2010. Linking aboveground and belowground food webs through carbon and nitrogen stable isotope analyses. Ecological Research 25: 745-756.

Hyodo, F. 2015. Use of stable carbon and nitrogen isotopes in insect trophic ecology. Entomological Science 18: 295-312.

Lanteri, A.A.; Guedes, J.V.C.; Parra, J.R.P. 2002. Weevils injurious for roots of citrus in São Paulo state, Brazil. Neotropical Entomology 31: 561-569.

Lavandero, B.; Wratten, S.; Hagler, J.; Jervis, M. 2004. The need for effective marking and tracking techniques for monitoring the movements of insect predators and parasitoids. International Journal of Pest Management 50: 147-151.

Maher, B.J.; Logan, D.P. 2004. Comparison of host plant preferences, fecundity and longevity for diet-reared and fieldcollected Fuller's rose weevil. New Zealand Plant Protection 57: 183-190.

Masaki, M.; Kadoi, M. 1997. Host plants of Pantomorus cervinus (Boheman) and relationship between fecundity or longevity and its host plants. Research Bulletin of the Plant Protection Service 33: 1-6.

Masaki, M.; Nakahara, S. 2000. Larval growth of the Fuller's rose weevil Pantomorus cervinus (Boheman) (Coleoptera: Curculionidae). Research Bulletin of the Plant Protection Service 36: 21-26.

McCutchan Jr., J.H.; Lewis, W.M.; Kendall, C.; McGrath, C.C. 2003. Variation in trophic shift for stable isotope ratios of carbon, nitrogen, and sulfur. Oikos 102: 378-390.
Minagawa, M.; Wada, E. 1984. Stepwise enrichment of ${ }^{15} \mathrm{~N}$ along food chains: further evidence and relation between $\delta^{15} \mathrm{~N}$ and animal age. Geochimica et Cosmochimica Acta 48: 1135-1140.

Oulhote, Y.; Le Bot, B.; Deguen, S.; Glorennec, P. 2011. Using and interpreting isotope data for source identification. Trends in Analytical Chemistry 30: 302-312.

Ouyang, F.; Cao, J.; Liu, X.; Men, X.; Zhang, Y.; Zhao, Z.; Ge, F. 2015. Tracing dietary origins of aphids and the predatory beetle Propylea japonica in agricultural systems using stable isotope analyses. Entomologia Experimentalis et Applicata 155: 87-94.

Ponsard, S.; Bethenod, M.T.; Bontemps, A.; Pélozuelo, L.; Souqual, M.C.; Bourguet, D. 2004. Carbon stable isotopes: a tool for studying the mating, oviposition, and spatial distribution of races of European corn borer, Ostrinia nubilalis, among host plants in the field. Canadian Journal of Zoology 82: 1177-1185.

Post, D.M. 2002. Using stable isotopes to estimate trophic position: models, methods, and assumptions. Ecology 83: 703718.

Prasifka, J.; Heinz, K. 2004. The use of C3 and C4 plants to study natural enemy movement and ecology, and its application to pest management. International Journal of Pest Management 50: 177-181.

Rounick, J.S.; Winterbourn, M.J. 1986. Stable isotopes and carbon flow in ecosystems. BioScience 36: 171-177.

Schellhorn, N.A.; Bianchi, F.J.J.A.; Hsu, C.L. 2014. Movement of entomophagous arthropods in agricultural landscapes: links to pest suppression. Annual Review of Entomology 59: 559-581.

Smith, B.N.; Epstein, S. 1971. Two categories of ${ }^{13} \mathrm{C} /{ }^{12} \mathrm{C}$ ratios for higher plants. Plant Physiology 47: 380-384.

Thompson, J.N. 1998. The evolution of diet breadth: monophagy and polyphagy in swallowtail butterflies. Journal of Evolutionary Biology 11: 563-578.

Wise, D.H.; Denise, M.; Moldenhauer, D.M.; Juraj Halaj, J. 2006. Using stable isotopes to reveal shifts in prey consumption by generalist predators. Ecological Applications 16: 865-876.

Ye, L.F.; Xue Fu, X.; Ouyang, F.; Xie, B.Y.; Ge, F. 2014. Determining the major Bt refuge crops for cotton bollworm in North China. Insect Science 22: 829-839. 